See discussions, stats, and author profiles for this publication at: https://www.researchgate.net/publication/307554107

\title{
Osseointegration of Ti-30Ta Implants without Primary Stability: Effect of
} Tranexamic Acid

Article in Materials Science Forum · August 2016

DOI: 10.4028/www.scientific.net/MSF.869.918

CITATIONS

0

9 authors, including:

Maria Cristina Rosifini Alves Rezende

São Paulo State University

115 PUBLICATIONS 238 CITATIONS

SEE PROFILE

Mário Jefferson Quirino Louzada

91 PUBLICATIONS 166 CITATIONS

SEE PROFILE
49

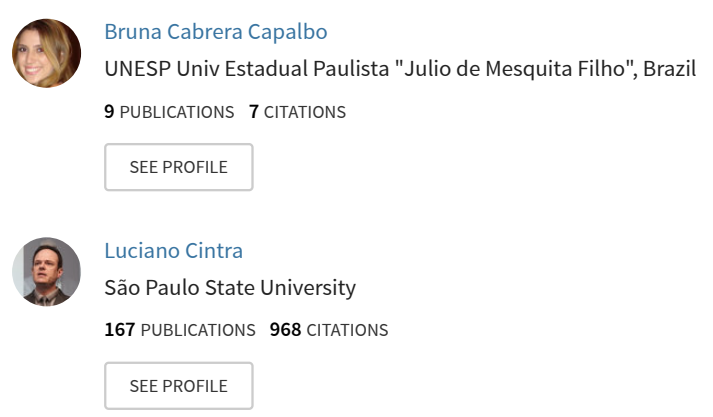

Some of the authors of this publication are also working on these related projects:

Effect of phodynamic thetapy on the mechanical properties and bond strength of glass-fiber posts to endodontically treated intraradicular dentin View project

Growth of semiconductor films using reactive sputtering View project 


\title{
Osseointegration of Ti-30Ta Implants without Primary Stability: Effect of Tranexamic Acid
}

\author{
Maria Cristina Rosifini Alves Rezende ${ }^{1, a}$, Bruna Cabrera Capalbo ${ }^{1, b}$, \\ Mario Jefferson Quirino Louzada ${ }^{2, \mathrm{c}}$, André Luiz Reis Rangel ${ }^{3, \mathrm{~d}}$, \\ Luciano Ângelo Cintra, ${ }^{1, \mathrm{e}}$, João Augusto Guedes de Oliveira, ${ }^{3, \mathrm{f}}$, \\ Paulo Noronha Lisboa-Filho ${ }^{4, g}$, Cristiane Mayumi Wada ${ }^{5, h}$ \\ and Ana Paula Rosifini Alves Claro ${ }^{3, i}$ \\ ${ }^{1}$ Faculdade de Odontologia de Araçatuba, Universidade Estadual Paulista \\ "Júlio de Mesquita Filho" UNESP, Brasil \\ ${ }^{2}$ Faculdade de Medicina Veterinária de Araçatuba, Universidade Estadual Paulista \\ "Júlio de Mesquita Filho" UNESP, Brasil \\ ${ }^{3}$ Faculdade de Engenharia de Guaratinguetá, Universidade Estadual Paulista \\ "Júlio de Mesquita Filho" UNESP, Brasil
}

${ }^{4}$ Faculdade de Ciências de Bauru, Universidade Estadual Paulista "Júlio de Mesquita Filho" UNESP, Brasil
${ }^{5}$ Pós-Graduação em Ciências dos Materiais (POSMAT), Universidade Estadual Paulista "Júlio de Mesquita Filho" UNESP, Brasil
arezende@foa.unesp.br, bbrucapalbo@hotmail.com, ${ }^{\mathrm{c} l o u z a d a @ f m v a . u n e s p . b r, ~}$ louzada@fmva.unesp.br, 'andre.mat06@yahoo.com.br, Iucianocintra@foa.unesp.br, faugustoguedes@hotmail.com, ${ }^{9}$ plisboa@fc.unesp.br; 'cris_may_25@hotmail.com, hrosifini@feg.unesp.br,

Keywords: alloys, titanium, tantalum, wound healing, tranexamic acid.

\begin{abstract}
A large clot formed between the inside of the bony wall of the extraction socket and the immediate implant surface may have premature breakdown. Tranexamic acid (TXA) is fibrinolysis inhibitor and an analog of the amino acid lysine. In this paper the influence of tranexamic acid on the osseointegration of $\mathrm{Ti}-30 \mathrm{Ta}$ implants without primary stability was investigated. Were fabricated 32 implants of CP Titanium Grade 4 and 32 implants of Ti-30Ta alloy with dimensions of $2.1 \times 2.8 \mathrm{~mm} \varnothing$. Bone defects of $2.5 \times 3.2 \mathrm{~mm} \varnothing$ were created in right tibia of 64 Wistar male-rats using a small round bur. They were divided $(n=16)$ into: Group I (CP-Ti machined implant), Group II (CP-Ti machined implant/ tranexamic acid), Group III (Ti-30Ta implant) and Group IV (Ti-30Ta implant/ tranexamic acid). The surgical defects of the Group II and Group IV were bathed with 20 $\mathrm{ml}$ of the tranexamic acid solution. The animals were euthanized at 45 days postoperative. In the right tibia of half each group ( 8 animals $/ 8$ tibiae) the maximum torque value necessary for manual removal of each implant was measured in Newton centimeters $(\mathrm{Ncm})$. The right tibia of other half each group was subjected to non-decalcified histology processing (Stevenel's blue/Alizarin red). Data were analyzed statistically (Kruskal-Wallis Analyses) and demonstrated significant differences $(\mathrm{P}<0.05)$ among groups. The values of group I were significantly lower than group III and IV, but without significant difference than group II both removal torque and peri-implant bone healing. The results suggest that: a) peri-implant bone formation occurred more rapidly around the Ti-30Ta implant; b) tranexamic acid favored the stabilization of blood clot and bone formation around Ti30Ta implants and not influenced bone formation around Ti-CP implants.
\end{abstract}

\section{Introduction}

The development of titanium implant provides more therapeutic options on the contemporary dentistry. [1]. It was particular interest to develop titanium alloys produced from nontoxic elements and that present a good balance of the properties of Ti-Ta alloys [2,3]. Using 30\% of 
tantalum has been shown the presence the presence of $\alpha^{\prime}$ martensite phase and ensure high strength and low Young's modulus, allowing biomedical application [3].

Dental implants are primarily anchored in bone by means of mechanical interlocking. Soon, anchoring primary delayed may occur when implants are installed into an alveolus immediately after the extraction. This occurs because of the large interface between the inside of the bony wall of the extraction socket and the implant surface after installation [4].

Several studies have evaluated the interference of blood clot in the wound healing of interface between osseous tissue and the implant [5-7]. Wound healing comprises a waterfall of events that the body brings into play to resolve the injury through stop of bleeding, restore function and to prevent infection. The stable hemostatic plug is strengthened by the fibrin mesh formed from platelet aggregation. Platelet activation causes the release of cytokines such as platelet-derived growth factor (PDGF) what will trigger the subsequent steps [2, 5-12]. In the absence of clotting disorders, hemostasis occurs within minutes of the initial damage [5-7].

Fibrinolysis with the clot breakdown is a normal response to tissue damage $[5,7,13]$. The molecular modeling of fibrinolysis shows a disaggregation of the fibers of fibrin by activated plasmin. Its resistance to lysis arises directly from its network architecture [14]. A large clot formed between the inside of the bony wall of the extraction socket and the immediate implant surface may have premature breakdown [5,7].

Tranexamic acid (TXA) is fibrinolysis inhibitor and an analog of the amino acid lysine. TXA competes with lysine for inhibition of plasminogen activation and the binding of plasmin to fibrin. Soon TXA inhibits the fibrin degradation [15, 16]. Antifibrinolytic drug, such as TXA, can prevent early clot breakdown [13]. Tranexamic acid (TXA) seems to present a support action for coagulation already in progress [14]. When this agent is applied in topical mode can produce the similar efficacy of systemic use without the higher absorption and the higher risk for thromboembolic complications [16]. Some authors have suggested that topical tranexamic acid can reduce blood loss and transfusion rates in orthopedic surgery $[16,17]$.

In this paper the influence of tranexamic acid in the osseointegration of Ti30Ta implant installed without primary stability was investigated.

\section{Material and Method}

It were fabricated 32 implants of CP Titanium Grade 4 and 32 implants of Ti-30Ta alloy with dimensions of $2.1 \times 2.8 \mathrm{~mm} \varnothing$. Ti $(99 \%)$ and $\mathrm{Ta}(99 \%)$ were combined by a melting process in a high purity argon atmosphere; re-melted ten times and held in the molten state for 3 - 4 minutes due to the titanium and tantalum there are differing densities (Ti:1953 K, $4.51 \mathrm{~g} / \mathrm{cm} 3$ and Ta: 3273 $\mathrm{K}, 16.6 \mathrm{~g} / \mathrm{cm} 3$ ) and the wide-phase differential (liquid and solid) in the binary Ti-Ta phase diagram [18-23]. All ingots were homogenized in a vacuum at $1100^{\circ} \mathrm{C}$ for $86.4 \mathrm{ks}$ in order to eliminate the as-cast microscopic chemical segregation and the residual stress caused by plastic deformation on the elastic modulus. The alloy was then cold-worked by a rotary swaging process (rotation speed 1000 rpm) using a CNC lathe ZIL (Centur 30S, ROMY, Brazil) [9].

The experimental protocol used 64 Wistar male-rats weighing 250-300g (45-day-old). All procedures on the rats were performed under general systemic anesthesia $(70 \mathrm{mg} / \mathrm{kg}$ ketamine and $10 \mathrm{mg} / \mathrm{kg}$ intramuscular xylazine) in a sanitary operating environment in compliance with the rules of Regulations of the work using experimental animals, CONCEA, Brazil. Approval was obtained from the animal care committee at the College of Dentistry, Araçatuba, UNESP.

For the surgical procedure the bone surface of the right tibia was exposed by a longitudinal incision. Bone defects of $2.5 \times 3.2 \mathrm{~mm} \varnothing$ were created using a small round bur. The created holes were treated to each group with one of the following treatment modalities $(n=16)$ : Group I (CP-Ti machined implant), Group II (CP-Ti machined implant/ tranexamic acid), Group III (Ti-30Ta implant) and Group IV (Ti-30Ta implant/ tranexamic acid). The surgical defects of the Group II and Group IV were bathed with $20 \mathrm{ml}$ of the tranexamic acid solution at a concentration of $3 \mathrm{~g}$ TXA per $100 \mathrm{ml}$ saline, as was found effective in prior studies [15]. All experimental areas were covered with $4 / 0$ black silk suture. The rats recovered from anesthesia without complications. They were given 
pain medication ( $25 \mathrm{mg}$ diclofenac sodium) during the first 3 days after surgery and an antibiotic (ampiclox $500 \mathrm{mg}$ I.M.) for 1 week to prevent infection. The necessary sample size was calculated using statistical software (nQuery Advisor, Statistical Solutions) and was based on the data of average CTF $(\mathrm{N} / \mathrm{cm})$ values and standard deviations (SDs) according to health status and treatment modalities measured in a preliminary pilot study. A sample size of eight animals per group was required for the detection of significant differences ( $80 \%$ power, two-sided $5 \%$ significant level).

The animals were euthanized at 45 days postoperative. The tibia bone was resected without encroaching on the grafted area using a bone saw. Then the right tibia of half each group (8 animals/8 tibiae) was placed in a workbench vise to ensure correct alignment with a torque meter with a scale range of 3-24 Ncm and divisions of $0.05 \mathrm{Ncm}$ (Tohnichi, Model 15-BTG-N, Tokyo, Japan). A wrench was adapted to the implant head to apply a counterclockwise movement to remove the implant, and the maximal torque value necessary for manual removal of each implant was measured in Newton centimeters $(\mathrm{Ncm})$. The right tibia of other half each group was immediately fixed in $10 \%$ phosphate buffered formaldehyde solution for $48 \mathrm{~h}$ and was subjected to non-decalcified histology processing. In brief, the retrieved samples were dehydrated in a graded series of ethanol and thereafter were infiltrated and embedded in methyl methacrylate. The embedded resin blocks were then subjected to non-decalcified histologic sectioning where the samples were first perpendicularly sectioned into slices with a slow-speed precision diamond saw (Isomet 2000; Buehler Ltd, Lake Bluff, IL, USA). After gluing the sections to a plexiglass with a light curing acrylate-based adhesive (Technovit 7210 VLC adhesive, Heraeus Kulzer GMBH; Wehrheim, Germany), the samples were grinded and polished under abundant water irrigation using a series of silicon carbide (SiC) papers $(400,600,800,1200)$ (Buehler Ltd) until a final thickness of $30 \mu \mathrm{m}$. Thereafter, the sections were then stained in Stevenel's blue/Alizarin red. The area of visibly distinguishable bone (tissue stained in red) within the implant thread chamber at X200 magnification was calculated as bone area fraction occupancy (BAFO) using X50-200 magnification (Leica DM2500M; Leica Microsystems GmbH, Wetzlar, Germany) by means of specialized computer software (Leica Application Suite; Leica Microsystems GmbH). The measurements were performed by a single evaluator according Sennerby et al. [24]. Data were analyzed statistically (Kruskal-Wallis Analyses). Differences were considered statistically significant if $\mathrm{p}<0.05$.

\section{Results}

Histologic observation showed bone formation in close contact to the implant for all groups (Figures 1 and 2). Statistical evaluation of the effects of material associated with tranexamic acid on the BAFO measures used Kruskal-Wallis test (Dunn Test) with significance $5 \%(\mathrm{~h}=17.8706$; $\mathrm{p}=0.0005$ ) revealed that the average percentage of bone area in Group I was significantly lower in relation to the other groups III and IV and without differences with Group II (Table 1). When we analyzed the influence of tranexamic acid (TXA) on bone area formation it was possible to observe a significant difference in Group III in relation to group IV, with the higher values for Ti-30Ta implant group. For Ti-CP implants were not found differences.

The results of the removal torque showed similar results at histomorphometric analysis. The values $(\mathrm{Ncm})$ of group I were significantly lower than group III and IV, but without significant difference than group II. Other important observation was that the removal torque of the implant, for the same treatment (TXA) was affected by the material of implant. Thus, Ti-30Ta alloy produced the higher values when compared CP-Ti. Statistical evaluation of the effects of material associated with tranexamic acid on the removal torque measures used Kruskal-Wallis test (Dunn Test) with significance $5 \%(\mathrm{~h}=17.8840 ; \mathrm{p}=0.0005)$ showed $10.30 \mathrm{Ncm}$ for Group I, $13.30 \mathrm{Ncm}$ for Group II, $14.80 \mathrm{Ncm}$ for Group III and $16.85 \mathrm{Ncm}$ for Group IV (Table 2).

Histomorphometric analysis showed $59.78 \%$ of bone area fraction occupancy for Group I, $68.36 \%$ for Group II, $85.90 \%$ for Group III and $92.62 \%$ of bone volume for Group IV (Table 1). 


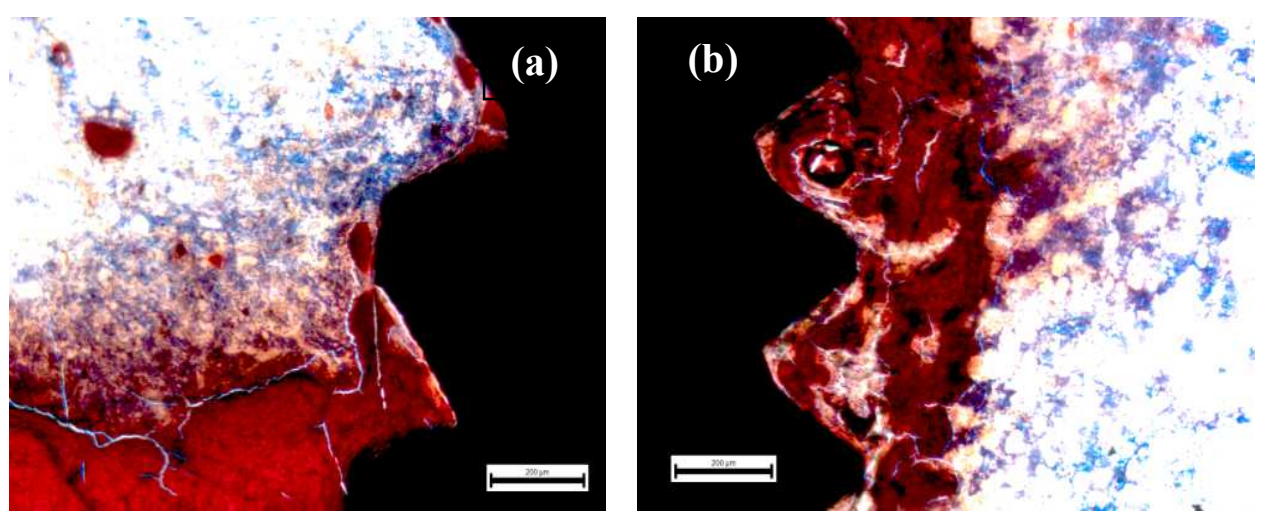

Fig. 1. Histological sections of bone between the threads of the implant in group I. (a) and group II (b). 20x magnification.
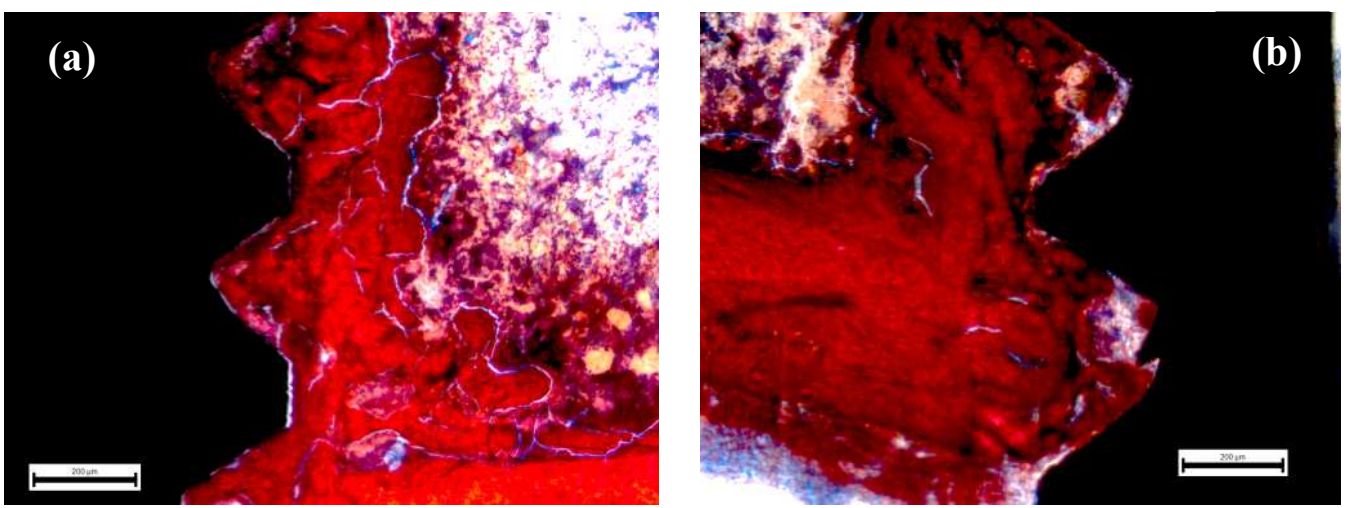

Fig. 2. Histological sections of bone between the threads of the implant in group III (a) and group IV (b). 20x magnification.

Table 1. Mean and standard deviation of bone area fraction occupancy among the groups

\begin{tabular}{c|c}
\hline Group & Mean/Standard Deviation \\
\hline Group I & $59.78 \pm 1.0378^{*}$ \\
\hline Group II & $68.36 \pm 1.1803$ \\
\hline Group III & $85.90 \pm 0.5745$ \\
\hline Group IV & $92.62 \pm 0.8075^{* *}$ \\
\hline${ }^{*}$ Significant difference related to group III and to group IV \\
**Significant difference related to group II
\end{tabular}

Table 2. Median, mean and standard deviation of removal torque of the implants among the groups

\begin{tabular}{c|c}
\hline Group & Mean/Standard Deviation \\
\hline Group I & $10.30 \pm 0.1904 *$ \\
\hline Group II & $13.30 \pm 0.6736$ \\
\hline Group III & $14.80 \pm 0.5916$ \\
\hline Group IV & $16.85 \pm 0.0500^{* *}$ \\
\hline *Significant difference related to group III and to group IV \\
**Significant difference related to group III
\end{tabular}

\section{Discussion}

Wound healing comprises a cascade of events that the body brings into play to resolve injury. Nature's first priorities are to stop bleeding, restore function and to prevent infection. Generally, the wound-healing events are grouped into four phases: hemostasis, inflammatory, proliferative/ repair and remodeling [5]. Blood vessel and tissues are severed after dental implant is placed in the bone. Within seconds, the interface between vessel and blood is altered, promoting platelet adhesion to newly exposed subintimal structures because substances, that normally are not in direct contact with the blood flow (collagen and von Willebrand factor) are exposed. The negative charge of the titanium devices can too allow the platelets to adhere to implant surface. Once a platelet adheres to the surface, they are formed platelets aggregates that serve to form a 
platelet plug over damaged area $[7-10,25,26]$. Later, clot dissolution occurs from plasminogen transformed to plasmin that will break down the fibrin. Early break down of the fibrin clot affects proliferation phases [7].

Tranexamic acid (TXA) is a lysine analogue. TXA reversibly binds lysine-binding sites of plasminogen and thus prevents the conversion of plasminogen to plasmin [27]. TXA is a drug with special characteristics: inexpensive, easily used and relatively safe [28]. Researchers have demonstrated the efficacy of this drug as a topical agent to prevent premature lysis of clot [29, 30].

In this study the stabilization of fibrin clot by TXA contributed for the bone formation more rapidly around the Ti-30Ta implant only. In this condition, TXA not only facilitated bone formation, but it also accelerated the synthesis of osseous tissue. Our results showed too that the material of the implant, titanium or titanium alloy was significant for improve osseous healing. Comparison between CP-Ti implant (Group I) and Ti-30Ta implant (Group III) showed that the incorporation of tantalum on $30 \%$ weight was statically significant for bone area fraction occupancy (59.78\% against $85.90 \%$, respectively).

The results of implant removal torque in this study showed similar results. There was statistically significant difference between the Group I related to group III and IV and without differences with Group II. For Ti-30Ta implants the higher values for removal torque were found in TXA group. These findings are in agreement with histomorphometric analyses.

Soon, although the histomorphometric and torque removal analysis of this study were not performed in the same animal, the percentage of bone area fraction occupancy had a positive relationship to the torque, i.e., Group IV had higher bone area and higher retention of the implant in the bone. Related to group I all these parameters were lower than in group III and IV and statistically similar to those in Group II.

\section{Conclusion}

Results suggested that: a) peri-implant bone formation occurred more rapidly around the Ti30Ta implant than Ti-CP implant; b) tranexamic acid favored the stabilization of blood clot and bone formation around Ti-30Ta implants and not influenced bone formation around Ti-CP implants.

\section{References}

[1] C.L. Liu: Compend. Contin. Educ. Dent. Vol. 26 (2005), p. 653.

[2] A.P.R. Alves Claro, J.A.G. Oliveira, A.L.A. Escada, L.M.F. Carvalho, M.J.Q. Louzada, M.C.R. Alves Rezende, Histological Analysis of the Osseointegration of Ti-30Ta Dental Implants After Surface Treatment, in: A. Öchsner, L.F.M. Silva, H. Altenbach (Eds.), Characterization and Development of Biosystems and Biomaterials, Springer, Berlim, 2013, pp.175-182.

[3] P. Capellato, N. Riedel, J. Williams, J. Machado, K. Popat, A. Claro: Engineering Vol. 5 (2013), p. 707.

[4] G. Favero, D. Botticelli, G. Favero, B. Garcia, T. Mainetti , N.P. Lang: Clin. Oral Impl. Res. Vol. 24 (2013), p. 7.

[5] M.C.R. Alves Rezende, A.P.M. Bertoz, C.R. Grandini, M.J.Q. Louzada, A.P. de Araújo Santos, B.C. Capalbo, A.P.R.A. Claro: Health Invest. Vol. 1 (2012), p. 33.

[6] B.B. Bezerra, M.A.M. Brazão, M.L. Campos, M.Z. Casati, E.A. Sallum, A.W. Sallum: Clin. Oral Impl. Res. Vol. 23 (2012), p. 938.

[7] T. Okamoto, R. Okamoto, M.C.R. Alves Rezende, M.F. Gabrielli: Braz. Dent. J. Vol. 5 (1994), p. 85.

[8] J.A.G. Oliveira, A.L.A. Escada, M.C.R.A. Rezende, M.B. Mathor, A.P.R.A. Claro: Clin. Oral Impl. Res. Vol. 23 (2012), p. 511.

[9] A.L.A. Escada, J.P.B. Machado, S.G. Schneider, M.C.R.A. Rezende, A.P.R.A. Claro: J. Mater. Sci. Mater. Med. Vol. 23 (2011), p. 2457.

[10] M.C.R. Alves-Rezende, S.F.C. Dekon, C.R. Grandini, A.P.M. Bertoz, A.P.R. Alves-Claro: SBF. Rev. Odontol. Vol. 32 (2011), p. 38. 
[11] M.A, Packham: Can. J. Physiol. Pharmacol. Vol. 72 (1994), p. 278.

[12] G. Gaetano: Haematologica Vol. 86 (2001), p. 349.

[13] L. Luz, A. Sankarankutty, E. Passos, S. Rizoli, G.P. Fraga, B. Nascimento Jr: Rev. Col. Bras. Cir. Vol. 39 (2012), p. 77.

[14] B.R. Hamlin, A.M. DiGioia, A.Y. Plakseychuk, T.J. Levison, Topical versus intravenous tranexamic acid in total knee arthroplasty, J Arthroplasty (2014), http:// dx.doi.org/10.1016/ j.arth.2014.10.007

[15] P.M. Mannucci:. N. Engl. Med. Vol. 339 (1998), p. 245.

[16] G. Konig, B.R. Hamlin, J.H. Waters: J. Arthroplasty Vol. 28 (2013), p. 1473.

[17] L. Zhaohui, G. Wanshou, Z. Qidong, Z. Guangduo: J. Orthop. Sci. Vol. 19 (2014), p. 948.

[18] Y.L. Zhou, M. Niinomi: Mater. Sci. Eng. Vol. 29 (2009), p. 1061-1065.

[19] Y.L. Zhou, M. Niinomi: J. Alloys Compd. Vol. 466 (2008), p. 535.

[20] Y.L. Zhou, M. Niinomi, T. Akahori, Changes in Mechanical Properties of Ti Alloys in Relation to Alloying Additions of Ta and Hf, 14th Int. Conf. Strength. Mater. 483-484 (2008) 153156

[21] Y.L. Zhou, M. Niinomi, T. Akahori: Mater. Sci. Eng. A Vol. 384 (2004), p. 92.

[22] Y.L. Zhou, M. Niinomi, T. Akahori: Mater. Sci. Eng. A-Struct. Mater. Vol. 371 (2004), p. 283.

[23] Y.L. Zhou, M. Niinomi, T. Akahori, H. Fukui, H. Toda: Mater. Sci. Eng. A Struct. Mater. Vol. 398 (2005), p. 28.

[24] L. Sennerby, P. Thomsen, L.E. Ericsson: Int. J. Oral Maxillofac. Implants Vol. 7 (1992), p. 62.

[25] M.A. Packham: Can. J. Physiol. Pharmacol. Vol. 72 (1994), p. 278.

[26] R.E. Rumbaut: Microcirculation Vol. 12 (2005), p. 233.

[27] G.D. Wera, R.M. Garcia, V.M. Goldberg: Reducing Perioperative Bleeding with Antifibrinolytics, http://www.aaos.org/news/aaosnow/feb13/research5.asp

[28] B. Mitra, M. Fitzgerald, P.A. Cameron, R.L. Gruen: Lancet Vol. 25 (2010), p. 1049.

[29] G.F. Chimento, T. Huff, J.L. Ochsner Jr., M. Meyer, L. Brandner , S. Babin: J. Arthroplasty Vol. 28 (2013), p. 74.

[30] F. Bidolegui, G. Arce, A. Lugones, S. Pereira, G. Vindver: Open Orthop. J. Vol. 8 (2014), p. 250 . 